\title{
Listening Learning Strategies Employed by English Majors at the Saigon International University
}

\author{
Chau Thanh Nha, M.A. ${ }^{1}$, Nguyen Thi Hong Dung, M.A. ${ }^{2}$ \\ ${ }^{1}$ Van Lang University, Vietnam \\ ${ }^{2}$ Western Sydney University, Australia
}

\begin{abstract}
It is unarguable that listening is one of the most significant macro skills in the process of language acquisition and takes the vital part in communication. However, it requires learners to possess both language knowledge and contextual knowledge in order to achieve high effectiveness in learning this skill. Accordingly, learners are presumed to execute listening learning strategies to get a better understanding of what is being spoken. The study aimed to investigate English listening learning strategies unconsciously employed by English majors at The Saigon International University (SIU) and explore the students' level of frequency of employing these strategies. The mixed-methods study was conducted with the participation of 115 undergraduate students majoring in English. The quantitative data collected from the questionnaire were processed by SPSS (19.0), whereas content analysis was employed to analyze the qualitative data obtained from the semi-structured interview. The findings showed that cognitive strategies were identified as the most dominant listening learning methods, followed metacognitive strategies and socio-affective strategies. Among the particular listening, the top five most common strategies included listening for main ideas first and then details, listening to different kinds of input, connecting prior knowledge to the existing information of the text, applying the learned vocabulary and grammar to comprehend the content, and choosing the suitable listening texts.
\end{abstract}

Keywords: EFL listening comprehension, listening learning strategies, Vietnamese EFL context

Abbreviations: EFL: English as a Foreign Language, SIU: The Saigon International University

\section{INTRODUCTION}

It is widely acknowledged that listening plays a fundamental role in English language learning and teaching in the $21^{\text {st }}$ century. Mendelsohn (1994) concludes that with the total time spent on communication, listening occupies $40-50 \%$ whereas speaking occupies $25-30 \%$ followed by reading, 11 $16 \%$; and writing, about $9 \%$.

According to Rost (2001, p. 94), "a key difference between more successful and less successful acquirers relates in large part to their ability to use listening as a means of acquisition". Richards (2008) claims that the development in students' communicative skills and proficiency in a language much depends on the strategies they have employed.

From the real context of teaching and learning English listening comprehension at The Saigon International University, the author conducted a study with the aim of allowing SIU students to share what listening strategies they have been utilizing while learning listening. Remarkably, this study is hoped to be a significant contribution to the university, i.e. from the findings, SIU teachers could judge the effectiveness of the strategies used by English majors and then may give some practical recommendations to the students, and a good foundation for the future studies. Therefore, the two research questions were formulated as follows:

Research question 1: What are the listening learning strategies employed by English majors at the Saigon International University?

Research question 2: To what extent do the students follow the strategies? 


\section{AIMS AND OBJECTIVES OF THE STUDY}

Based on the aforementioned reasons and the reality of teaching and learning English listening at The Saigon International University, the author conducted a study with the aim of allowing SIU students to share what listening strategies they have been utilizing while learning listening.

\section{LiTERATURE REVIEW}

According to O'Malley \&Chamot (1990), there are three main types of listening comprehension strategies including cognitive strategies, metacognitive strategies and socio-affective strategies.

\subsection{Cognitive Strategies}

Cognitive strategy is considered a problem-solving technique that learners use to cope with the learning activities and make the process of acquiring the knowledge easier (Azmi, Celik, Yidliz, \&Tugrul, 2014). In a similar vein, Derry and Murphy (1986) state that cognitive strategy is a problemsolving method employed by the leaners in order to gain the knowledge and skills.

Moreover, Cross (2009), Vandergrift (2003, 1997), Chamot (2005), and Oxford (1990) identify cognitive strategies in a different way that they refer to the process of employing the other sub-strategies as follows.

- Inferencing strategy: the learners use the information to guess the meaning of the unfamiliar words associated with listening tasks or to support prediction based on co-contextual knowledge.

- Elaboration strategy: the learners use their prior knowledge relating to the information obtained from the listening texts in order to fulfill the understanding.

- Note-taking strategy: Learners write down key words while listening.

- Deduction strategy: Learners reach a conclusion about the target language. This strategy helps students to make guesses based on partial comprehension of the text.

- Summarization strategy: Learners try to recall or write a summary of the information about the listening text using the target language.

\subsection{Metacognitive Strategies}

Rubin (1988) defines metacognitive strategies as management methods employed by the students to manage their learning through the activities of organizing, examining, evaluating and altering. For example, for organizing strategies, learners become aware of what to listen and then utilize the specific features of the aural language input that help them understand the aural input easily. Similarly, students who adopt this strategy will know what to listen and when to listen for the information because they know how to organize, take control of, and verify the gathered information (Holden, 2004; Azmi, Celik, Yidliz, \&Tugrul, 2014). Wenden (1998) says that students who adopt this strategy can learn faster, retain the knowledge well, receive the information constantly, manage all contexts, be self-confident in getting support from teachers or friends, and evaluate themselves.

Richards (2008. p. 11) clearly identifies metacognitive strategies as "conscious and unconscious activities that perform an executive function in the management of cognitive strategies" including:

- Assessing the situation: Thinking carefully of the situation from a language task by checking listeners' own knowledge, listeners' available internal and external resources as well as the restrictions of the situations before taking part in a task

- Monitoring: Checking the effectiveness of the listener's own performance and another listener's while engaged in a task

- Self-evaluating: Checking the effectiveness of the listener's own performance and another listener's after taking part in a task

- Self-testing: Testing the listener himself to check the effectiveness of his own language use or the lack thereof.

\subsection{Socio-affective Strategies}

Cross (2009), Vandergrift (2003, 1997), Chamot (2005), and Oxford (1990) identify socio-affective strategies as the process of employing the three following strategies: 
- Cooperation strategy: listeners work with friends to complete a listening task and check the accuracy together.

- Question-for-clarification strategy: listeners ask their teachers or friends for explanation, clarification as well as feedback on what they have done with the listening task.

- Self-motivation strategy: listeners get some ways to relieve anxiety and encourage and remind themselves of making progress.

\section{Previous Studies}

Many studies have been conducted to find out the solutions to the problems of English listening comprehension. The authors of those studies have focused on the three main listening strategies including metacognitive strategies, cognitive strategies and socio-affective strategies.

With the purpose of exploring the most frequently used strategies among the students, the connection among strategy use and listening comprehension and self-efficacy, Kassem (2015) conducted a study with the participation of 84 second-year Egyptian students. The findings indicated that cognitive strategies were adopted the most by the participants, followed by metacognitive strategies and the socio-affective strategies. The reason for socio-affective strategies to be the least frequently employed solutions was because of the individualism in Egypt.

Similarly, in order to find out the correlation between the listening strategies and listening comprehension, Shahrokhi, Malekian, and Sayedi (2015) carried out a study with the participations of 64 male students who learned English as a foreign language at Sama junior high school in Iran. A listening comprehension test and a questionnaire were employed to collect the data. The results showed a considerable difference among the listening strategies in terms of the level of frequency of employing those strategies. Specifically, the more the learners employed the cognitive strategies, the more improvement in listening they achieved. Metacognitive strategies were judged to be the second most effective solutions helping learners produce their desired outcomes in listening. The last and least frequently adopted solutions were attached to socio-affective strategies.

Manzouri, Shahraki, and Fatemi (2016) undertook a study in order to investigate the listening strategies used by Iranian EFL students, and the dissimilarities between a group of proficient students and a group of less-proficient students in terms of the types of listening strategies utilized by each group. A sample independent t-test and a questionnaire were used for data collection. The study discovered that many students had a tendency to utilize cognitive strategies rather than metacognitive or socio-affective ones.

Not many learners have employed the listening strategies while listening or even they have sometimes applied one or two types of strategies. For example, Bao (2017) studied the listening strategies instructed by teachers and strategies employed by learners. The results showed that students tended to use cognitive strategies more than the others and even did not use socio-affective strategies at all, whereas teachers preferred using metacognitive strategies. However, Yi-Jiun (2014) had different findings that, regarding the three listening strategies, most of the students did not know how to utilize the listening strategies appropriately. Regarding metacognitive strategies, they did not plan, monitor and evaluate their listening. In terms of cognitive strategies, students tended to use bottom-up more than top-down. For socio-affective strategies, they hoped that their teachers could teach them more listening strategies. In brief, there was a gap in applying listening strategies (Yi-Jiun, 2014; Nowrouzi, Tam, Nimehchisalen, \&Zareian, 2015).

In the context of Vietnam, Le (2015) learned about the high school students' employment of listening strategies regarding domains including the use of grouped and individual listening strategies, the correlation between the frequent level of employing the strategies and listening ability, and the difference between a group of effective students and a group of less-effective students in terms of the types of listening strategies used by each group. There were 82 students participating in the listening comprehension test and the questionnaire survey which were the two main instruments. The results indicated one fact that the many students did not know very well about the listening strategies. Many students had no ideas what they were. The findings also suggested that fostering students' awareness of listening strategies helped them achieve better listening outcomes.

Ngo (2016) discovered students' development in proficiency after being taught an explicit listening strategy instruction. There were 27 second-year students at Tay Bac University participating in the 
study. Listening tests and interviews were employed to collect data. After 11 weeks, 22 sessions, consisting of 8 steps such as warm-up, revision, presentation, practice, evaluation, feedback from peers and teachers, expansion, and self-study, were taken place. The findings provided a fact that students' listening worked out positively in proportion to the high level of frequency of employing the strategies. Besides, listening strategies instructions used for classroom activities were also applied for listening practices outside the classroom such as watching English channels, listening to music, etc.

Duong, Tran, and Tran (2018) conducted a study to learn about eleventh grader's actual use of English listening learning strategies at Duong Van Duong High School. A mixed-methods research approach was employed in which both quantitative and qualitative data were collect by means of close-ended questionnaire and semi-structured interview with the participation of 425 eleventh graders responding to the questionnaire and 20 interviewees. The findings showed that students' levels of frequency of employment of listening learning strategies were different. Specifically, cognitive and affective strategies were reported as the most frequently used methods, followed by the group of metacognitive and social strategies, and the group of compensation and memory strategies.

\section{Methodology}

The present study was conducted with a mixed-methods research approach by collecting both quantitative and qualitative data. Concerning the quantitative research method, according Bryman (2001), the quantitative research method focuses on the work with numbers or figures in data collection and analysis and can be regarded as being scientific in nature. This research method is more connected to the objectivities and validities of what has been observed or surveyed. Regarding the qualitative research method, this kind of method fosters the close connection and interaction between the researchers and the respondents (Borg \& Gall, 1989). This type of study can help avoid implementing the testing of questions and hypotheses (Bogdan \& Biklen, 1992; Borg \& Gall, 1989). In addition, Bouma \&Atkison (1995, p. 208) claim that "some subjects are best investigated using quantitative approach whilst for others; qualitative approaches will give better results. However, in some cases both methods can be used." Accordingly, the present study employed a mixed-methods research approach with the aim of making the results reliable and valid.

\subsection{Participants}

This study was conducted with the participation of one hundred and fifteen English majors (male: $38 \%$; female: $62 \%$ ) conveniently sampled in responding to the questionnaire. Their age ranged from eighteen to twenty-five. In addition, $51 \%$ of the participants spent from fifteen to one hour per day learning listening comprehension at home, whereas there were $13 \%$ of students spending one hour and a half to three hours and a half, $8 \%$ of students spending more than three hours and a half, and $28 \%$ of students stating that it depended on their free time. In addition, twelve students were called for a semi-structured interview.

\subsection{Research Instruments}

The quantitative and qualitative data were collected through means of a close-ended questionnaire and a semi-structured interview. The questionnaire was adapted from Bao's (2017), and Simasangyaporns' (2016) questionnaires including two parts. In Part I, the participants were asked to provide their demographics by answering the first four questions about genders, age range, academic year and time for listening. Part II focused on listening learning strategies they have been using. In order to answer the questions in Part II, the participants were asked to choose the appropriate level for five close-ended items designed in 5 -point Likert scale $(1=$ never, $2=$ rarely, $3=$ sometimes, $4=$ often, $5=$ always). The questionnaire was translated into Vietnamese in order that participants could clearly understand the questions.

With regard to the semi-structured interview, two main questions and follow-up questions were asked to collect students' responses on listening learning strategies. In addition, in order to get in-depth information, Vietnamese language was used during the interviews.

\subsection{Data Collection and Analysis Procedures}

The questionnaire in Vietnamese was administered to 115 English majors during the class time in about fifteen minutes without any preparation. This was done one week before the last week of the first semester. The participants answered the questionnaire with the support from the teacher 
researcher for any clarifications. In addition, the semi-structured interview was set up with the participation of twelve students of English who were called for the interviews individually. The answers to the interview questions were recorded and transcribed.

The data obtained from the questionnaire were analyzed by means of SPSS 19.0 in which descriptive statistics including mean, standard deviation were produced to find out students' most frequently used strategies.

Content analysis approach was employed to analyze the data obtained from the interview in three steps. Firstly, the data were presented in a form, read again and again, and classified into different types of information. Secondly, the data were coded and recoded and then grouped into the same categories. Interpretation and summary were made in the last step. The interviewees were marked from the first (SI1) to the twelfth (SI12).

\section{FINDINGS AND DISCUSSIONS}

As mentioned in the above section, the questionnaire was designed in 5-point Likert scale $(1=$ never, $2=$ rarely, $3=$ sometimes, $4=$ often, $5=$ always). Based on calculated interval coefficient for four intervals in five scale, $(4 / 5=0.80)$ intervals were arranged. Therefore, the following criteria in the Likert Scale were used to interpret the data: $1.00-1.80=$ never; $1.81-2.60=$ rarely; $2.61-3.40=$ sometimes; $3.41-4.20=$ often; 4.21-5.00 = always.

\subsection{Overall Results}

The descriptive statistics results of the three English listening learning strategies were displayed in Table 1 to show an overall picture of listening strategies used by the English majors.

Table1.Overall Statistics Results of English Listening Learning Strategies

\begin{tabular}{|c|l|c|c|}
\hline Themes & \multicolumn{1}{|c|}{ Listening Learning Strategies } & Mean (M) & Standard Deviation (SD) \\
\hline 1 & Cognitive Strategies & 3.51 & .75 \\
\hline 2 & Metacognitive Strategies & 3.19 & .65 \\
\hline 3 & Socio-affective Strategies & 3.10 & .76 \\
\hline
\end{tabular}

$(1.00-1.80=$ never; $1.81-2.60=$ rarely; $2.61-3.40=$ sometimes; $3.41-4.20=$ often; $4.21-5.00=$ always $)$

Table 1 shows the overall descriptive statistics results of the three main listening strategies including metacognitive strategies, cognitive strategies and socio-affective strategies in the present study. The results were presented in a descending order based on the mean score values. Specifically, the group of cognitive strategies was placed at first with the total score value of $\mathrm{M}=3.51$, and $\mathrm{SD}=.75$, and followed by metacognitive strategies $(\mathrm{M}=3.19, \mathrm{SD}=.65)$ and socio-affective strategies $(\mathrm{M}=3.10$, $\mathrm{SD}=.76$ ). Of the three listening learning strategies, cognitive strategies were employed at the most frequent level. In addition, the mean score value of cognitive strategies was belonged to the scale limit of "3.41-4.20" which means "often". Therefore, it could be concluded that English majors "often" used cognitive strategies while listening so as to handle the listening problems. Next, also based on the mean score value, metacognitive strategies were labeled as the second most frequently used listening solutions, followed by socio-affective strategies as the third/last most frequently used solutions. Besides, the mean scores of these two groups of strategies were belonged to the scale limit of "2.61-3.40" which means "sometimes". Hence, these two groups of listening strategies were "sometimes" employed by English majors while listening.

\subsection{Metacognitive Strategies}

The descriptive statistics results for the questionnaire in terms of Mean and Standard Deviation for the first group of listening strategies including six items $(1,2,3,4,5$, and 6) in order to learn about the frequently-used level of metacognitive strategies perceived by English majors were presented in Table 2. In addition, the qualitative results of the semi-structured interview were also discussed to illuminate the findings.

Table2. Results of Metacognitive Strategies

\begin{tabular}{|c|l|c|c|}
\hline Items & \multicolumn{1}{|c|}{ Metacognitive Strategies } & Mean (M) & Standard Deviation (SD) \\
\hline 1 & I have a plan in my mind on how I am going to listen. & 3.28 & 1.11 \\
\hline 2 & I choose the listening texts which are not beyond my ability. & 3.50 & 1.03 \\
\hline 3 & I read the audio scripts for unfamiliar words and consult & 3.49 & 1.09 \\
\hline
\end{tabular}




\begin{tabular}{|c|c|c|c|}
\hline & dictionaries for meaning and pronunciation. & & \\
\hline 4 & I try to listen to speakers with different accents. & 3.43 & 1.09 \\
\hline 5 & I review the listening materials in a planned way after class. & 2.42 & 1.04 \\
\hline \multirow[t]{2}{*}{6} & $\begin{array}{l}\text { After listening, I reflect how I have listened, and about what } \\
\text { I might do differently next time. }\end{array}$ & 3.02 & 1.11 \\
\hline & Average & 3.19 & .65 \\
\hline
\end{tabular}

$(1.00-1.80=$ never; $1.81-2.60=$ rarely; $2.61-3.40=$ sometimes; $3.41-4.20=$ often; $4.21-5.00=$ always $)$

According to the data presented in Table 4.7, metacognitive strategies were "sometimes" adopted by English majors to sidestep their listening problems and improve their listening skills demonstrated by $M=3.19$. However, based on students' perspectives, some strategies in this group had overwhelming influences on listening comprehension performance. In specific, choosing the suitable listening text was the dominant solution that was "often" employed by most of the students to sidestep listening problems (item 2, M=3.50, $\mathrm{SD}=1.03$ ). Similarly, strategies of reading the audio scripts for unfamiliar words (item 3, M=3.49, SD=1.09), and listening to different accents (item 4, M=3.43, SD=1.09) were "often" utilized by students to sidestep listening problems as well. In addition, the strategies marked items 1 and 6 in this group were "sometimes" followed by English majors to advance their listening comprehension. Students "sometimes" had a plan in their mind on how they were going to listen (item $1, \mathrm{M}=3.28, \mathrm{SD}=1.11$ ). Next, they also "sometimes" evaluated their work and set a better plan for the next listening practice (item 6, M=3.02, $\mathrm{SD}=1.11$ ). Contrary to other strategies, reviewing the listening materials in a planned way was "rarely" implemented by the students (item $5, \mathrm{M}=2.42$, $\mathrm{SD}=1.04)$.

The interview was carried out to discover how frequently the participants employed the listening strategies to deal with listening problem. In terms of metacognitive strategies, all participants (100\%) answered that they used listening strategies to improve their listening. Specifically, 5 participants (41.7\%) often had a plan on how they were going to listen, including SI1, SI2, SI4, SI5, and SI11. Furthermore, 8 participants (66.7\%) excluding SI1, SI5, SI9 and SI11 utilized the strategy of choosing the suitable listening materials. In addition, reading the audio scripts was the solution that 9 participants (75\%), except SI2, SI11 and SI12 employed to understand the content of the listening text and enrich their vocabulary. Besides, $50 \%$ of the participants, including SI3, SI4, SI5, SI8, SI10, and SI12 tried to listen to speakers with different accents. Moreover, there were three students $(25 \%)$, including SI1, SI4, and SI11, answering that they endeavored to review the materials at home to get a deeper understanding of the content. Finally, SI1, SI4, SI5, and SI11 (33.3\%) responded that they usually evaluated how well they had performed after completing a listening task. Among the interview's participants, SI4 was the one who employed a majority of listening strategies to improve her listening skill.

I usually skimmed the questions and decided what questions would be answered first. I also read the audio scripts to check my work, and took notes of unknown words to learn. I usually listened to different accents.

I often reviewed the materials to remedy the mistakes. I usually chose the listening texts with different levels of difficulties to practice. I also evaluated what I had done. (SI4)

In conclusion, choosing suitable listening texts in terms of level of difficulties was perceived the dominant metacognitive strategy by the students. Before listening, they formulated a plan in their mind on what and how they were going to listen. Moreover, they referred to the audio scripts for unknown words and checked their meaning and pronunciation. In order to be judged to be good at listening, it required listeners to understand a variety of accents, so students tried to listen to spoken texts by speakers with different accents. After listening, students employed evaluation strategy to measure how well they had done, recognize what mistakes they had made, and decide what to do for the later practices. Theoretically, Rubin (1988) defines metacognitive strategies as management methods employed by the students to manage their learning in terms of organizing, examining, evaluating and altering. For example, for metacognitive organizing strategies, learners become aware of what to listen and then utilize the specific features of the aural language input that help learners understand the aural input easily. Similarly, students who adopted this strategy would know what to listen and when to listen for the information because they knew how to organize, take control of, and verify the gathered information (Holden, 2004; \& Azmi, Celik, Yidliz, \&Tugrul, 2014). Besides, Wenden (1998) affirms that students who use this strategy can learn faster and retain the knowledge well, receive the information constantly, manage all contexts, be self-confident in getting support from teachers or friends, and evaluate themselves. Furthermore, the group of metacognitive strategies is believed to facilitate the learners to "oversee, regulate, or direct the language learning process" 
(Vandergrift, 1997, p. 170). According to Oxford (1990), employing metacognitive strategies is process of planning, monitoring, and evaluating the learning process, preparing suitable conditions to learn, setting the learning goals and assessing the outcomes.

Although the effectiveness of metacognitive strategies in promoting listening comprehension practices was clearly stated, the participants in the present study did not employ them very often. Quantitatively, based on the mean score value for this group of strategy, the level of frequency of employing the strategies in this group was "sometimes". When being asked in the interview, some of the respondents stated that they learned listening instinctively, they did not know how to name the methods they were applying to learn listening. They said that since those ways were effective, they kept employing them and did not know any other useful methods either. Likewise, Yi-Jiun (2014) found that most of the students did not know how to utilize the listening strategies appropriately. Regarding metacognitive strategies, they did not know how to plan, monitor and evaluate their listening.

\subsection{Cognitive Strategies}

The descriptive statistics results for the questionnaire in terms of Mean and Standard Deviation for the second group of listening strategies including seven items $(7,8,9,10,11,12$, and 13) in order to learn about the frequently-used level of cognitive strategies perceived by English majors were presented in Table 3. In addition, the qualitative results of the semi-structured interview were also discussed to illuminate the findings.

Table3.Results of Cognitive Strategies

\begin{tabular}{|c|l|c|c|}
\hline Items & \multicolumn{1}{|c|}{ Cognitive Strategies } & Mean(M) & \multicolumn{1}{|c|}{$\begin{array}{c}\text { Standard } \\
\text { Deviation(SD) }\end{array}$} \\
\hline 7 & I listen for main ideas first and then details. & 3.66 & 1.08 \\
\hline 8 & $\begin{array}{l}\text { I practice listening using different kinds of input such as lectures, } \\
\text { radio news, songs, films, etc. }\end{array}$ & 3.88 & 1.14 \\
\hline 9 & $\begin{array}{l}\text { I make mental or written summary of key information of the text } \\
\text { while listening. }\end{array}$ & 3.43 & 1.20 \\
\hline 10 & $\begin{array}{l}\text { I apply the vocabulary, phrases and grammar I have learned to } \\
\text { understand the content. }\end{array}$ & 3.83 & .98 \\
\hline 11 & $\begin{array}{l}\text { I connect my prior knowledge to the existing information of the } \\
\text { heard text. }\end{array}$ & 3.71 & 1.07 \\
\hline 12 & I translate the content into Vietnamese while listening. & 3.00 & 1.33 \\
\hline 13 & I wear earphones or headphones while listening. & 3.08 & 1.32 \\
\hline & Average & $\mathbf{3 . 5 1}$ & $\mathbf{. 6 5}$ \\
\hline
\end{tabular}

(1.00-1.80 = never; $1.81-2.60=$ rarely; 2.61-3.40 = sometimes; 3.41-4.20 = often; 4.21-5.00 = always)

Unlike the metacognitive strategies, a significant portion of the participants "often" employed cognitive most of the cognitive strategies while listening by which the focus was placed for practicing listening using different kinds of input such as lectures, radio news, songs, films, etc. (item 8, $\mathrm{M}=3.88, \mathrm{SD}=1.14$ ), followed by applying the vocabulary, phrases and grammar the students have learned to understand the content (item $10, \mathrm{M}=3.83, \mathrm{SD}=.98$ ), listening for main ideas first and then details (item 7, M=3.66, $\mathrm{SD}=1.08$ ), connecting prior knowledge to the existing information of the heard text (item 11, M=3.71, SD=1.07), and making written and mental summaries of key information of the heard text (item 9, M=3.43, SD=1.20). The rest of the cognitive strategies were "sometimes" used by most of the students. In detail, students "sometimes" adopted the strategies of wearing earphones or headphones while listening (item 12, M=3.08, $\mathrm{SD}=1.32$ ) and translating the content into Vietnamese (item 12, M=3.00, $\mathrm{SD}=1.33$ ) to deal with listening problems.

In the interview, the students were asked if they used cognitive strategies while listening to gain better results, they all answered "yes". 3 respondents (25\%), including SI4, SI7 and SI11, affirmed that they first listened for main ideas and then specific information. Not many students practiced listening using different sources; the proof of this was that only two participants (16.7\%), including SI3 and SI10, applied this solution. In contrast, 10 out of 12 participants (83\%), excluding SI5 and SI7, replied that they usually made a summary of key information of the text while listening. Moreover, applying the learned vocabulary, phrases and grammar to catch on to the content was applied by 5 interviewees (41.7\%), including SI1, SI3, SI7, SI8, and SI12. Besides, that prior knowledge was very important to comprehend the content of the listening text was reported by 4 participants (33.3\%) consisting of SI1, 
SI3, SI4, and SI7. According to the responses from the interviewees, many of them did not find the strategy of translating the content into Vietnamese while listening helpful, whereas 4 other students (33.3\%) including SI5, SI6, SI8, and SI12 affirmed that this solution was effective in helping them achieve desired outcomes. Finally, there were only two students (16.7\%) having the positive answers towards the strategy of wearing earphones or headphones while listening (SI3 and SI4). A sample response from SI3 who have employed most of the cognitive strategies was extracted as follows.

I usually listened to different sources to enhance my social knowledge and get familiar to different accents. I often took note of the key information while listening. My prior knowledge helped me understand better. I usually wore earphones to avoid the disturbing things outside. However, I could not distinguish the main ideas and details. And, I found translation time-consuming and useless. (SI3)

In summary, many students preferred practicing listening by using different kinds of input. Next, they applied their language knowledge while listening. They had a tendency to listen for the main ideas first and then details. In addition, their prior knowledge helped them a lot in comprehending the context. Furthermore, making a summary was an effective cognitive strategy for the participants in the current study. This finding agrees with Kassem's (2015) finding which showed that cognitive strategies were adopted the most by the participants in order to improve their listening comprehension skill. Similarly, Shahrokhi, Malekian and Sayedi (2015) also found that the more the learners employed the cognitive strategies, the more improvement in listening they achieved. In a same vein, another finding also affirmed that many students preferred employing cognitive strategies while listening (Manzouri, Shahraki, \&Fatemi, 2016). More worthily, the finding in agreement with Duong, Tran, and Tran's (2018) which showed that cognitive strategies were preferably used by most of the students. In conclusion, cognitive strategies occupied the dominant role in the students' process of learning listening. Since, when students practiced listening using many different kinds of input, they gave themselves chances to get familiar with different accents, advance their socio knowledge. Besides, translation strategy as a facilitator helped listeners to understand the content more clearly, helped them learn more new words and grammar structures. Next, students' prior knowledge relating to the listening topics supported them in comprehending the content when there were some problems caused by the speakers' pronunciation, accents, intonation, etc.

\subsection{Socio-Affective Strategies}

Coupled with the aforementioned strategies, the author added four more questionnaire items for the last group of listening learning strategies, socio-affective strategies, numbered 14, 15, 16 and 17 in order to explore how frequently students have employed this group of strategies to deal with the problems. The qualitative data obtained from the questionnaire were also analyzed in Table 4to clarify the results of the questionnaire. Consistently, the qualitative results were provided as supplements.

Table4. Results of Socio-Affective Strategies

\begin{tabular}{|c|l|c|c|}
\hline Items & Socio-Affective Strategies & Mean(M) & Standard Deviation(SD) \\
\hline 14 & $\begin{array}{l}\text { I ask for explanation or verification from the teachers or } \\
\text { peers. }\end{array}$ & 3.18 & 1.14 \\
\hline 15 & I collaborate with peers to learn and check the tasks. & 3.19 & 1.07 \\
\hline 16 & $\begin{array}{l}\text { I encourage myself to relieve anxiety by reminding } \\
\text { myself of my progress. }\end{array}$ & 3.21 & 1.09 \\
\hline 17 & I give myself a reward when I fulfill a listening task. & 2.82 & 1.39 \\
\hline & Average & $\mathbf{3 . 1 0}$ & $\mathbf{. 6 6}$ \\
\hline
\end{tabular}

$(1.00-1.80=$ never; $1.81-2.60=$ rarely; $2.61-3.40=$ sometimes; $3.41-4.20=$ often; $4.21-5.00=$ always $)$

Table 4 reveals that socio-affective strategies, in general, were "sometimes" employed by most of the participants in the present study $(\mathrm{M}=3.10, \mathrm{SD}=.76)$. In particular, in terms of frequency of employment for each strategy in this group, the strategy of self-encouragement to relieve listening anxiety was identified as the dominant solution (item 16, M=3.21, $\mathrm{SD}=1.09$ ), followed by strategies of collaborating with peers to learn and check the task (item $15, \mathrm{M}=3.19, \mathrm{SD}=1.07$ ), asking for explanation or verification from teachers or peers (item 14, $\mathrm{M}=3.18, \mathrm{SD}=1.14$ ), and self-rewarding (item 17, $\mathrm{M}=2.82, \mathrm{SD}=1.39$ ).

When being asked whether or not they employed socio-affective strategies, 10 out of 12 participants' answer $(83.0 \%)$ was "yes", excluding SI3 and SI10. In detail, asking for explanation or verification from teachers or friends was effective, reported by 8 participants $(66.7 \%)$, except SI3, SI6, SI8 and SI10. Similarly, collaborating with friends to learn and check the tasks was considered the workable 
solution by 8 interviewees (66.7\%), aside from SI3, SI8, SI9 and SI10. Perhaps, self-encouragement was a vital factor helping all the students relieve anxiety and try to make progress, as 10 out of 12 participants (83.0\%) said that they always encouraged themselves to get better in listening, apart from SI1 and SI3. More significantly, 10 respondents (83.0\%) said that fulfilling a listening task was a great reward for them, so they did not give themselves anything, except for SI6 and SI10. For example, SI5 explained very clearly why he found some of the socio-affective strategies effective.

I asked teachers and friends for explanation in order to check what I did right and what I did wrong. Besides, studying with friends was a chance for mutual support between us; we could exchange the learning methods with one another. I encouraged myself not to stop practicing because I acknowledged that no one could help me except myself. I thought that having finished a listening exercise with high results was a big present for me. (SI5)

To sum up, English majors "sometimes" employed socio-affective strategies to improve their listening. In other words, they did find this strategic group helpful in sidestepping listening difficulties and bettering their listening skill. In addition, the data generated from the interview revealed that ten out of twelve interviewees utilized these socio-affective strategies very often.

Cross (2009), Vandergrift (2003, 1997), Chamot (2005), and Oxford (1990) identify socio-affective strategies as the process of employing the three strategies including cooperation, question-forclarification and self-motivation. The first strategy fosters the cooperation among listeners to complete a listening task and check the accuracy together. Many students in the present study believed that learning with peers helped them mutually check their work, share the useful learning methods.

Regarding the question-for-clarification strategy, listeners ask their teachers or friends for explanation, clarification as well as feedback on what they have done with the listening task (Cross, 2009; Vandergrift, 2003\&1997; Chamot, 2005; Oxford,1990). The finding in the present study showed that teachers and friends as facilitators could show listeners what mistakes they made, and give them advice on how to do better.

The last is self-motivation strategy. Listeners get some ways to relieve anxiety and encourage and remind themselves of making progress (Cross, 2009; Vandergrift, 2003 \& 1997; Chamot, 2005; Oxford, 1990). Several participants affirmed that self-motivation played an influential role in their learning process. Thinking of the progress they have been made, they have fostered themselves to try more and more for getting a higher level.

It is interesting to compare this finding with that found by Duong, Tran, and Tran (2018) who found that many students admitted the importance of social-affective strategies in positively helping them deal with listening difficulties.

\section{CONCLuSion}

\subsection{Summary of the Research Findings}

The investigation of the listening learning strategies has shown that most of English majors participating in the present study have employed listening learning strategies while listening. Many students preferably employed cognitive strategies in dealing with listening problems while learning. In addition, the second most frequently employed solutions were occupied by metacognitive strategies, followed by socio-affective strategies. Among the particular listening strategies helping students to get round the aforementioned problems, the top six most common solutions were listening for main ideas first and then details, listening to different kinds of input, connecting prior knowledge to the existing information of the text, applying the learned vocabulary and grammar to comprehend the content, choosing the suitable listening texts, and reading the audio scripts for new words and for a better understanding of the content, while the top six least common strategies included reviewing the materials at home, evaluating, translating the content into Vietnamese, wearing earphones while listening, asking teachers or peers for explanation or verification, and self-rewarding.

\subsection{Pedagogical Implications}

\subsubsection{For Students}

The evidence from this study suggests that students should employ cognitive strategies in combination with metacognitive and socio-affective strategies in order to increase the effectiveness in listening. 
Firstly, students should be fostered to be self-equipped with vocabulary in different fields of knowledge through listening practices using different kinds of input. By using different resources to practice listening, students could gradually get familiar with different accents and advance contextual and language knowledge.

Secondly, students should come up with a plan on what and how to listen, evaluate the results after listening and review the listening texts in a planned way after school.

Thirdly, it is suggested that students should read the audio scripts of the listening texts to gain deeper understandings of the contents. Besides, reading practices also help students to advance not only their context knowledge but also their language knowledge.

Fourthly, teachers and friends are considered the trusted and helpful facilitators. Accordingly, it is advisable that students should consult their teachers and friends on what they do not know or the listening results they have produced. In addition, cooperating with friends is one of the best ways to learn listening since students can mutually support and share the knowledge and what they have experienced in learning listening with one another.

\subsubsection{For Teachers}

In respect of teachers, it is recommendable that different types of input should be provided in order to enhance students' background and linguistic knowledge with the support of teachers in terms of explanation or verification for the linguistic features. Besides, teachers should learn about the students' learning styles so as to choose the suitable listening materials to meet their interests.

Moreover, feedback on students' listening performance is necessary since it could encourage their error correction and strengthen their motivation. More worthily, positive feedback should be given more than the negative comments with the aim of offering incentives to students to make better progress.

It is important that teachers should help students to understand clearly what they are expected to do with metacognitive strategies, cognitive strategies and socio-affective strategies. After fully comprehending the listening strategies, students are able to practice listening autonomously and effectively.

\subsection{Recommendations for Further Research}

It would be interesting to assess the effectiveness of employing the listening strategies while listening in class by means of observation and independent sample t-test. It would also be worthwhile to compare experiences of students among each academic year of the listening learning strategies they have used. Moreover, further research in this field would be great help in investigating the differences in terms of listening strategies used between proficient listeners and non-proficient listeners. Last but not least, further work needs to elaborately examine the links between the listening problems and strategies.

\section{REFERENCES}

[1] Azim, N. M., Celik, B., Yidliz, N., \&Tugrul, M. C. (2014). Listening comprehension difficulties encountered by students in second language learning class. Journal of Education and Instructional Studies in the World, 4(4), 1-6.

[2] Bao, X. (2017). A study on listening strategies instructed by teachers and strategies used by students. International Journal of English Linguistics, 7(2), 186-195.

[3] Bogdan, R. C., \& Biklen, S. K. (1992). Qualitative research for education: an introduction to theory and methods. Boston: Allyn and Bacon.

[4] Borg, W. R., \& Gall, M. D. (1989). Educational research: an introduction. New York: Longman.

[5] Bouma, G. D., \& Atkinson, G. B. J. (1995). A handbook of science social research. London: Oxford University Press.

[6] Bryman, A. (2001). Social research methods. New York: Oxford University Press.

[7] Chamot, A. U. (2005). Language learning strategy instruction: current issues and research. Annual Review of Applied Linguistics, 25, 112-130.

[8] Cross, J. (2009). Effects of listening strategy instruction on new videotext comprehension. Language Teaching Research, 13(2), 151-176. 
[9] Derry, S. J., \& Murphy, D. A. (1986). Designing systems that train learning ability: from theory to practice. Review of Educational Research, 56, 1-39.

[10] Duong, M. T., Tran, T. H. T., \& Tran, Q. T. (2018). Eleventh graders' actual use of English listening learning strategies at Duong Van Duong high school. VNU Journal of Foreign Studies, 1(35), 114-130.

[11] Holden, W. R. (2004). Facilitating listening comprehension: acquiring successful strategies. Bulletin of Hokiruku University, 28, 257-266.

[12] Kassem, H. M. (2015). The relationship between listening strategies used by Egyptian EFL college sophomores and their listening comprehension and self-efficacy. English Language Teaching, 8(2), 153169.

[13]Le, H. T. H. (2015). An investigation into listening strategies of EFL students within the high school setting. Asian Journal of Education Research, 3(4), 21-34.

[14] Manzouri, H., Shahraki, A., \&Fatemi, S. (2016). Effect of listening proficiency on types of listening strategies used by Iranian EFL learners. International Journal of English Language and Translation Studies, 30-41.

[15] Mendelsohn, D. J. (1994). Learning to listen: A Strategy-based approach for the second language learner. San Diego: Dominie Press.

[16] Ngo, T. H. N. (2016). The impact of listening strategy instruction on listening comprehension: a study in an English as a foreign language context. Electronic Journal of Foreign Language Teaching, 13(2), 245-259.

[17] Nowrouzi, S., Tam, S. S., Nimehchisalem, V., \&Zareian, G. (2015). Iranian EFL students' listening comprehension problems. Theory and Practice in Language Studies, 5(2), 263-269.

[18] O’Malley, J. M., \&Chamot, A. U. (1990). Learning strategies in second language acquisition. Cambridge: Cambridge University Press.

[19] Oxford, R. L. (1990). Language learning strategies: What every teacher should know. New York: Newberry House.

[20] Richards, J. C. (2008). Teaching listening and speaking: from theory to practice. Cambridge: Cambridge University Press.

[21] Rost, M. (2001). Teaching and researching listening. London: Longman.

[22] Rubin, J. (1988). Improving foreign language listening comprehension. Washington DC: US Department of Education.

[23] Shahrokhi, M., Malekian, P., \&Sayedi, S. B. (2015). Listening comprehension ability and the use of listening strategies by Iranian Pre-Intermediate EFL learners. Journal of Applied Linguistics and Language Research, 2(5), 231-241.

[24] Simasangyaporn, N, (2016). The effect of listening strategy instruction on Thai learners' self-efficacy, English listening comprehension and reported use of listening strategies. Published Dissertation of Doctor of Philosophy, University of Reading, Thailand.

[25] Vandergrift, L. (1997). The strategies of second language (French) listeners: A descriptive study. Foreign Language Annals, 30(3), 387-409.

[26] Vandergrift, L. (2003). Orchestrating strategy use: towards a model of the skilled L2 listener. Language Learning, 53(3), 463-496.

[27] Wenden, A. (1998). Metacognitive knowledge and language learning. Applied Linguistics, 19(4), 515-537.

[28] Yi-Jiun, J. (2014). A study of English listening strategies applied by technological university students. Journal of Daojiang University, 127-142.

\section{AUTHORS' BIOGRAPHIES}

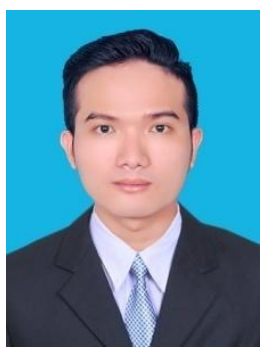

Mr. Chau Thanh Nha, is currently a full-time lecturer of English at Van Lang University (VLU). Besides, he had over two years' experience teaching English skills to English majors and non-English majors at The Saigon International University from August 2016 to October 2018. More than that, he has been teaching English at Duong Minh Language School for over 4 years. He has extensive experience working with EFL students of all ages including kids, teenagers and adults. He earned Master's Degree in English Language at Ho Chi Minh City University of Technology in July 2019. His academic areas of interest mostly lie in TESOL methodology, language skills, and applied linguistics. 


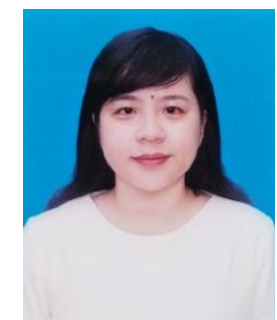

Ms. Nguyen Thi Hong Dung, was a full-time lecturer of English at The Saigon International University (SIU) - Ho Chi Minh City, Vietnam. She earned her master's degree in TESOL at Victoria University, Australia. Apart from working as a lecturer for Diploma's and Bachelor's programs at universities in Ho Chi Minh City, she worked as an international program manager at SIU and an academic director at an English language center in Ho Chi Minh City. At present, she is studying abroad for her Master of Education (Leadership and Management) at Western Sydney University, Australia.

Citation: Chau Thanh Nha, Nguyen Thi Hong Dung. "Listening Learning Strategies Employed by English Majors at The Saigon International University" International Journal on Studies in English Language and Literature (IJSELL), vol 8, no. 7, 2020, pp. 16-27. doi: http://dx.doi.org/10.20431/2347-3134.0807003.

Copyright: () 2020 Authors. This is an open-access article distributed under the terms of the Creative Commons Attribution License, which permits unrestricted use, distribution, and reproduction in any medium, provided the original author and source are credited. 